American Journal of Pharmaceutical Education 2021; 85 (4) Article 8365.

\title{
RESEARCH
}

\section{Exploring the Career Engagement, Interests, and Goals of Pharmacy Students Identifying as Underrepresented Racial Minorities}

Faustina T. Hahn, PharmD, ${ }^{\mathrm{a}}$ Antonio A. Bush, PhD, MS, ${ }^{\mathrm{a}, \mathrm{b}}$ Kate Zhang, PhD, ${ }^{\mathrm{c}}$ Ami Patel, PharmD, Kimberly Lewis, PharmD, ${ }^{\mathrm{e}, \mathrm{f}}$ Anita Jackson, MD, MPH, ${ }^{\mathrm{g}}$ Jacqueline E. McLaughlin, PhD, MS ${ }^{\mathrm{a}}$

${ }^{a}$ University of North Carolina at Chapel Hill, Eshelman School of Pharmacy, Chapel Hill, North Carolina

${ }^{\mathrm{b}}$ Association of American Medical Colleges, Washington, District of Columbia

${ }^{\mathrm{c}}$ Duke University, Office of the Dean of Students, Durham, North Carolina

d eNOVA, New Providence, New Jersey

${ }^{\mathrm{e}}$ G. V. (Sonny) Montgomery VA Medical Center, Jackson, Mississippi

f Student National Pharmaceutical Association, Buies Creek, North Carolina

${ }^{g}$ Durham County Department of Public Health, Durham, North Carolina

Submitted August 25, 2020; accepted December 15, 2020; published April 2021.

Objective. To examine pharmacy career engagement, interest, and confidence in Doctor of Pharmacy (PharmD) students identifying as underrepresented racial minorities (URMs).

Methods. A 15-item survey about career engagement, confidence, and goals was administered at a business session of a national conference. The survey included demographic items and items about career exposure prior to and during school, career aspirations after graduation, frequency of engagement in various settings, career factors, and career confidence. Cronbach alpha was used to examine survey reliability. Descriptive statistics and nonparametric statistical tests were used to analyze survey responses.

Results. Sixty-nine URM students completed the survey. Most indicated frequent engagement with community pharmacy prior to and during school; no engagement with hospital pharmacy prior to school, yet occasional or frequent engagement during school; and no engagement with the pharmaceutical industry prior to and during school. Most selected hospital pharmacy as their career aspiration, followed by community pharmacy and industry. Approximately half indicated an interest in completing a postgraduate fellowship. Items selected as important to career choice included patient care, job security, and level of stress. Group differences were found by gender and year in school.

Conclusion. Despite calls for diversity in pharmacy, there is a paucity of research in this area. This study provides a first glimpse into the career engagement, confidence, and goals of students identifying as URMs, raising a number of critical issues for pharmacy education. Moving forward, schools, employers, and researchers must work to better understand the career development of URM students, including barriers and facilitators to access and success.

Keywords: diversity, survey, career interest, pharmacy education

\section{INTRODUCTION}

The US population is becoming increasingly racially and ethnically diverse, with the population of underrepresented racial minorities (URMs) (ie, Black and/or African American, Hispanics and/or Latino/a, American Indian/Alaska Native, and Native Hawaiian/Other Pacific Islander $)^{1}$ projected to increase from $30 \%$ to $54 \%$ by

Corresponding Author: Jacqueline E. McLaughlin, University of North Carolina at Chapel Hill, Eshelman School of Pharmacy, 322 Beard Hall, Chapel Hill, NC 27599. Tel: 919-966-4557. Email: Jacqui_mclaughlin@unc.edu
2050. ${ }^{1-4}$ However, the current makeup of the US pharmacist workforce does not reflect the growing racial and ethnic diversity of the country. In 2019, approximately $64.5 \%$ of 341,000 pharmacists in the United States selfidentified as White, $22.1 \%$ as Asian, $10.5 \%$ as Black and/ or African American, and 2.7\% as Hispanic and/or Latino/a. ${ }^{4,5}$ Research suggests that because of structural racism, URM groups tend to receive poorer quality of care and have poorer health outcomes from preventable and treatable diseases than the general population. ${ }^{6-11} \mathrm{Un}$ derrepresented racial minority patients are also more likely to trust health care professionals of similar racial or 


\section{American Journal of Pharmaceutical Education 2021; 85 (4) Article 8365.}

ethnic backgrounds. ${ }^{6-10}$ This may be a result of cultural and experiential similarities that promote mutual understanding and trust. ${ }^{10}$ Similarly, URM providers are more likely to practice in underserved communities and treat URM patients. ${ }^{12}$ This was predicted to be in part reflective of the URM providers' decisions to practice in areas with higher proportions of members of their own race or ethnic group. $^{13}$

Racial gaps between practitioners and patients have been emphasized by numerous calls to increase diversity within pharmacy schools and the profession. ${ }^{14-16}$ Hayes, for example, argued that rapid US diversification and lack of practitioners identifying as URMs in health care highlight the importance of URM recruitment and job placement in pharmacy schools. ${ }^{17}$ Similarly, Bush identified social barriers created by a lack of racial diversity that potentially threaten the sense of belonging among and retention of URM students. ${ }^{18}$ The American Association of Colleges of Pharmacy's (AACP) Argus Commission eschewed the lack of empirical research about URM experiences of pharmacy school applicants, current pharmacy students, pharmacy faculty, and AACP and its member institutions, and argued that more work must be done to demonstrate the profession's commitment to diversity. ${ }^{19}$

Despite these calls for diversity and diversity-related research, there is a scarcity of research in this area and a need to better understand the experiences and trajectories of URM populations in pharmacy education. ${ }^{20}$ More specifically, there is a critical need to gain insight into the career interests of URM pharmacy students. ${ }^{18}$ Although several studies describe pharmacy career goals among all students, they do not explicitly focus on or describe findings specifically from URM students, therefore, disproportionately highlighting non-minoritized groups. ${ }^{21,22}$ A noticeable knowledge gap exists with respect to the career goals of URM students. As such, the purpose of this study was to examine pharmacy career engagement, interest, and confidence in PharmD students identifying as URMs. This work was guided by the Eshelman School of Pharmacy's programmatic efforts and designed with the hope of expanding the small yet growing body of diversity literature in pharmacy education. ${ }^{18,20}$

\section{METHODS}

At the start of a business session of the 2017 national conference of a student organization, PharmD students were invited to complete a 15-item, paper-based survey about career engagement, confidence, and goals. This conference was selected because it hosts one of the largest gatherings of URM pharmacists and student pharmacists annually and focuses on serving the underserved. The survey was developed by a team of faculty and staff at the UNC Eshelman School of Pharmacy using existing research, professional expertise, and personal experience. Prior to the conference, the team reviewed the survey via email and provided suggestions for revision to address face validity (ie, were items written to assess what the researchers aimed to assess?) and content validity (ie, was anything missing?). A pilot study was conducted with postdoctoral fellows, and minor edits were made to the survey based on their feedback.

To explore career engagement, the survey included items about which career paths students had been exposed to during their training (participants were instructed to select all responses that applied) and which career they aspired to obtain after graduation (participants were instructed to select one response). Using a scale from $1=$ never to $4=$ frequently, students were also asked how often they engaged in professional activities (eg, community pharmacy, hospital pharmacy, academic research, academic teaching, pharmaceutical industry) prior to PharmD training and during PharmD training.

To explore career interests, students were asked to select all careers they aspired to pursue upon graduation (eg, community pharmacy, hospital pharmacy, academic research, academic teaching, pharmaceutical industry) and about the factors they believed were most important when considering a career on a scale from $1=$ of little importance to $4=$ very important (eg, patient care, flexibility, research, level of stress, geographic location, selfactualization). To explore their career confidence, students were asked to rate their confidence on a scale from $1=$ not at all confident to $10=$ highly confident in obtaining a job in various settings (eg, community pharmacy, hospital pharmacy, academic research, academic teaching, pharmaceutical industry, postgraduate fellowship/residency). The survey also gathered the following demographic data: age, year in school, gender, and race/ ethnicity.

Before data were analyzed, Cronbach alpha was used to test the reliability of survey items and yielded a result of .7, which is considered acceptable for internal consistency. ${ }^{23}$ Data were then analyzed using descriptive statistics and nonparametric statistical tests. Specifically, the Mann-Whitney U test was used to compare gender differences between PharmD students identifying as male or female, while the Kruskal Wallis test was used to compare differences between students enrolled in different years of the PharmD program. A chi-square test was used to compare participants' career aspirations by gender and school year. Continuous data are presented as mean and standard deviation, and categorical data are presented as frequency (percentage) or median (interquartile range). 


\section{American Journal of Pharmaceutical Education 2021; 85 (4) Article 8365.}

All analyses were conducted in SPSS, version 26 (IBM). This study was determined to be exempt from full review by the University of North Carolina Institutional Review Board.

\section{RESULTS}

One hundred forty-seven students completed the survey, of which 69 identified as being URMs (ie, African American, Hispanic/Latino, American Indian/Alaska Native, or Native Hawaiian/Pacific Islander). This group comprised $46.9 \%$ of all students who completed the survey $(n=147)$, with responses from non-URMs $(n=78)$ excluded because they fell outside the scope of the study. All URM students invited to participate completed the survey (100\% response rate). Of the 69 participants, most identified as Black/African American $(\mathrm{n}=56,81.2 \%)$ and female $(n=53,76.8 \%)$, with a mean age of $26.1 \pm 3.2$ years. Seventeen participants $(24.6 \%)$ were second professional year (P2) students, $30(43.5 \%)$ were third professional year (P3) students, and $22(31.9 \%)$ were fourth professional year (P4) students (Table 1).

When asked about career engagement, most participants indicated having frequent engagement with community pharmacy prior to school $(\mathrm{n}=38,55.1 \%)$ and during school ( $n=53,76.8 \%)$ (Table 2). Most participants reported never having engagement with hospital pharmacy prior to school $(n=42,60.9 \%)$, yet reported occasional $(n=22,31.9 \%)$ or frequent $(n=21,30.4 \%)$ engagement in this setting during school. Most participants reported never having engagement with the pharmaceutical industry prior to school $(n=59,85.5 \%)$ or

Table 1. Characteristics of Participants in a Survey of Pharmacy Students Who Identified as Being a Member of an Underrepresented Racial Minority $(\mathrm{N}=69)$

\begin{tabular}{lc}
\hline Characteristic & \\
\hline Age in years, Mean (SD) & $26.1(3.2)$ \\
Gender, N (\%) & $16(23)$ \\
$\quad$ Male & $53(77)$ \\
$\quad$ Female & \\
Race, N (\%) & \\
Black/African American & $56(81.2)$ \\
Hispanic/Latino & $13(18.8)$ \\
American Indian/Alaskan Native & $2(2.9)$ \\
Native Hawaiian/Pacific Islander & $1(1.4)$ \\
Year in program, N (\%) & $17(24.6)$ \\
Second year (P2) & $30(43.5)$ \\
$\quad$ Third year (P3) & $22(31.9)$ \\
\hline Fourth year (P4)
\end{tabular}

during school $(n=39,56.5 \%)$. Some participants reported having exposure to other types of careers within pharmacy, including compounding pharmacy $(\mathrm{n}=36,52.2 \%)$, clinical specialty $(n=34,49.3 \%)$, drug information $(n=20,29.0 \%)$, government $(n=17,24.6 \%)$, pharmacy law/public policy $(\mathrm{n}=16,23.2 \%)$, nuclear pharmacy $(n=12,17.4 \%)$, and home health $(n=7,10.1 \%)$. Participants identifying as female were more likely than those identifying as male to report having frequent exposure to community pharmacy during school $(p=.02)$. No differences in engagement with various careers were found by school year. Reliability of engagement items was $\alpha=0.7$.

When asked about which career they aspired to pursue, most participants selected hospital pharmacy $(n=41,59.4 \%)$, followed by community retail $(n=15$, $21.7 \%)$ and pharmaceutical industry $(\mathrm{n}=12,17.4 \%)$. Fewer than half of participants indicated they were interested in owning a business $(n=29,41.9 \%)$, and approximately half indicated that they were interested in completing a postgraduate fellowship $(\mathrm{n}=35,50.7 \%)$. There were no differences in career goal settings based on participants' gender or school year.

The items most commonly scored as very important or important to career choice included patient care $(n=66$, $95.7 \%)$, level of job security ( $n=66,95.7 \%)$, and level of stress $(n=65,94.2 \%)$ (Table 3). Conducting research $(n=8,11.6 \%)$ and geographic location $(n=20,29.0 \%)$ were the items most commonly scored as having little importance. The P2 students were less likely than the P3 and $\mathrm{P} 4$ students $(p=.03)$ to indicate that flexibility was important for career selection. No other differences were found among participants based on gender or school year. Reliability of career goal items was $\alpha=0.7$.

Participants were most confident in their ability to obtain a job in community pharmacy (median 10, IQR 910), followed by hospital pharmacy (median 8, IQR 6-9), and postgraduate fellowship/residency (median 7, IQR 59). Participants were least confident in their ability to obtain a job in academic teaching (median 5, IQR 3-7) and the pharmaceutical industry (median 5, IQR 3-7). No differences in confidence were found based on participants' gender or school year. Reliability of confidence items was $\alpha=0.8$.

\section{DISCUSSION}

Calls for diversity in pharmacy education, coupled with the lack of racial and ethnic diversity among practitioners, highlight the importance of better understanding pharmacy career engagement, interests, and goals among URM students. ${ }^{14-16,18,20}$ This study boasts one of the largest sample sizes of URM students from multiple institutions for a diversity-related study in pharmacy 


\section{American Journal of Pharmaceutical Education 2021; 85 (4) Article 8365.}

Table 2. Career Engagement, Confidence, and Goals of Participants in a Survey of Pharmacy Students Who Identified as Being a Member of an Underrepresented Racial Minority $(n=69)$

\begin{tabular}{|c|c|c|c|c|c|c|c|c|}
\hline \multirow[b]{2}{*}{ Desired Career Setting } & \multicolumn{2}{|c|}{$\begin{array}{c}\text { Career Engagement, } \\
\text { Prior to PharmD } \\
\text { Training }\end{array}$} & \multicolumn{2}{|c|}{$\begin{array}{c}\text { Career Engagement, } \\
\text { During PharmD } \\
\text { Training }^{\mathrm{a}}\end{array}$} & \multicolumn{2}{|c|}{$\begin{array}{l}\text { Career } \\
\text { Goals }\end{array}$} & \multicolumn{2}{|c|}{$\begin{array}{c}\text { Career } \\
\text { Confidence }\end{array}$} \\
\hline & $\mathbf{N}$ & $\%$ & $\mathbf{N}$ & $\%$ & $\mathbf{N}$ & $\%$ & Median & IQR \\
\hline Community practice & 44 & 63.7 & 62 & 89.9 & 15 & 21.7 & 10 & $9-10$ \\
\hline Health system/hospital practice & 17 & 23.6 & 45 & 65.2 & 41 & 59.4 & 8 & $6-9$ \\
\hline Academic research & 15 & 21.7 & 31 & 44.9 & 1 & 1.4 & 5 & $4-7$ \\
\hline Academic teaching & 10 & 14.5 & 25 & 36.2 & 5 & 7.2 & 5 & $3-7$ \\
\hline Pharmaceutical industry & 1 & 1.4 & 13 & 18.8 & 12 & 17.4 & 5 & $3-7$ \\
\hline
\end{tabular}

"N(\%) who responded "occasional" or "frequent" to "How often were you engaged in professional activities in each of the following settings [PRIOR TO or DURING] your PharmD training?" measured on a scale ranging from $1=$ never to $4=$ frequent

${ }^{\mathrm{b}} \mathrm{N}(\%)$ who selected "yes" in response to select all that apply for the item "Upon graduation which career as a PharmD do you aspire to obtain."

${ }^{c}$ Median and interquartile range (IQR) of responses to "On a scale of 1-10, how confident are you that you can obtain a job in each of the following settings?" measured on a scale ranging from $1=$ not at all confident to $10=$ highly confident

education. It also provides a critical first step towards understanding this essential yet mostly unexplored topic. ${ }^{24,25}$

Given historical workforce demands and the prevalence of community pharmacies in the US, we were not surprised that most participants had exposure to community pharmacy prior to and during their PharmD training, along with marking the highest confidence in obtaining a career in this setting. According to 2018 data from the United States Bureau of Labor Statistics, $43 \%$ of pharmacists hold positions at local pharmacies/drug stores while $26 \%$ hold positions at hospitals. ${ }^{26}$ In pharmacy education, Siracuse and colleagues reported that two out of three pharmacy students had pharmacy work experience at a chain pharmacy, including traditional chains, mass merchandiser chains, and grocery store chains. ${ }^{27}$ Additionally, community pharmacy has a lower

Table 3. Factors That Pharmacy Students Who Identified as a Member of an Underrepresented Minority Believed Were

Most Important When Considering a Pharmacy Career $(n=69)$

\begin{tabular}{lcc}
\hline Career Factor & $\mathbf{N}^{\mathbf{a}}$ & $\mathbf{\%}^{\mathbf{a}}$ \\
\hline Patient care & 66 & 95.7 \\
Level of job security & 66 & 95.7 \\
Level of stress & 65 & 94.2 \\
Flexibility of work & 64 & 92.8 \\
Self-actualization & 64 & 92.8 \\
Application of knowledge & 63 & 91.3 \\
Dynamic work schedule & 60 & 87.0 \\
Managerial responsibility & 51 & 73.9 \\
Geographical location & 46 & 66.7 \\
Research & 28 & 40.6 \\
\hline
\end{tabular}

"Participants who responded "important" or "very important" to the item "How important are the following areas when you consider your career choice?" as measured on a scale from $1=$ not at all important to $4=$ very important barrier to entry compared to other pharmacy environments like health systems or hospital, with many positions not requiring any additional training. ${ }^{28}$

Despite high levels of engagement in community pharmacy, most participants indicated an interest in health system/hospital pharmacy careers. The US Department of Labor predicts an increase in the number of hospital positions over the next decade because of the rapidly shifting health care landscape in which more pharmacists are integrated into health care teams. ${ }^{29,30}$ While students in this study indicated interest in clinical pharmacy roles, there are also known barriers to obtaining these positions, such as obtaining pharmacy residencies.

Postgraduate year 1 (PGY1) or 2 (PGY2) residencies are often a prerequisite for pharmacy jobs that require skills beyond those needed for an entry-level pharmacist positions. ${ }^{31}$ Furthermore, faculty and peers often encourage pharmacy students to consider postgraduate training. ${ }^{31}$ Most participants in this study indicated interest and confidence in postgraduate training; however, neither the number of URM PGY1 or PGY2 residents nor the match rates for URMs are publicly available, ${ }^{32}$ leaving some question about barriers to residencies and residency matching for these students. In other health care professions, such as orthopedic surgical residencies, URM applicants are enrolled at a lower rate than non-URM applicants, which may deter URM applicants, limit URM exposure to the field, and inhibit interaction with potential mentors. ${ }^{33,34}$ More research must be done and data must be shared by professional organizations, like the American Society of Health-System Pharmacy, to better understand URM interests and matching to residencies.

As it relates to the pharmaceutical industry, most participants reported very little pharmaceutical industry engagement prior to and during their PharmD training. 


\section{American Journal of Pharmaceutical Education 2021; 85 (4) Article 8365.}

However, the results suggest that those exposed to pharmaceutical industry during school had sustained interest in pursuing an industry career. Unfortunately, racial/ ethnic groups that are underrepresented in pharmacy are also underrepresented within the high technology sector, which includes pharmaceutical and medicine manufacturing, with African American and Hispanic employees comprising $7.4 \%$ and $8.0 \%$ of that workforce, respectively. ${ }^{35,36}$ Although data about individuals identifying as URMs in the pharmaceutical industry are scarce, research suggests that a lack of outreach towards URMs may inhibit recruitment and retention of members of this group within science and engineering sectors. ${ }^{37}$ Because of the lack of research and data concerning URMs in pharmaceutical industry, the best mechanisms for supporting schools and students interested in this career pathway remain unknown.

Few participants in this study indicated interest in pursuing academic careers in research or teaching. This deficit may be influenced by the lack of URM faculty in pharmacy education and the resulting race-match effect in which a teacher of the same race can effectively boost students' confidence and enthusiasm for learning. ${ }^{38-40}$ Birdsall and colleagues found that the race effect is stronger among non-white populations in legal education. ${ }^{39}$ Increasing faculty diversity in pharmacy is critical for enabling the race-match effect, creating supportive communities, advocating for students, and enhancing interest in academic careers. ${ }^{41,42}$ While the race-match effect exists, the onus of supporting and mentoring URM students should not fall solely on URM faculty. Non-URM faculty can play a critical role in mentoring URM students. Reddick and Pritchett, for example, found that White faculty who leveraged their formative experiences in mentoring provided essential opportunities to better serve students, fairly distribute mentorship, and improve morale among URM faculty populations. ${ }^{43}$ By creating an inclusive and welcoming environment, the mentoring relationship can thrive on common interest, social background, and simple mutual attraction rather than on race alone. ${ }^{43}$

Career goals are thought to be influenced through the process of development and determined by two types of factors: intrinsic factors, such as personal interest, and extrinsic factors, such as salary and cost of training. ${ }^{33}$ Participants in this study selected job security as a key factor in career goals, which is related to both intrinsic and extrinsic motivators for work. ${ }^{45}$ In addition, self-actualization was frequently selected as an important career factor. Self-actualization, according to Maslow, represents growth of an individual toward fulfillment of "being valued," also known as realization of the meaning in life. ${ }^{46}$ Intrinsic factors identified among URMs interested in health-related careers include wanting to develop ways of improving health, help one's racial or ethnic group make valuable contributions to society, care for people, and analyze information about people's health. ${ }^{47}$ Selfdetermination theory suggests that intrinsically motivated students are more likely to persist in health-science programs when faced with fiscal or temporal challenges. ${ }^{47}$ Dewsbury and colleagues, for example, found that sociocultural contexts such as economic outcomes, financial sacrifices, first generation student status, location, immigration status, gender, and other factors heavily influenced URM career paths and interests. ${ }^{48}$

While providing one of the first glimpses into pharmacy career interests among students identifying as URMs, this study raises several critical issues for schools and the profession of pharmacy. First, schools should take steps to better understand the career development of students identifying as URMs and how the educational environment influences career pathways. ${ }^{18}$ Schools should develop diversity and inclusion strategies for increasing the number of URM faculty and staff, focusing on recruitment and retention. Furthermore, increasing opportunities for URM student populations to explore different, perhaps nontraditional pharmacy careers, is critical for reducing barriers and empowering these students to understand and pursue pathways that align with their interests and abilities. Schools must create support programs that focus on aforementioned influences, such as postgraduate residency/fellowship seminar series geared to prepare URM PharmD students. Providing support for URM students can help them navigate their career paths, which in turn may help them reach out to future URM students.

There are several limitations to this study. First, even though data were collected at a single session of one of the largest annual gatherings of URM pharmacists and pharmacy students in the United States, the sample size was limited to those at the meeting. The demographic distribution of participants also varied slightly from that of pharmacy education overall in which female students constituted $65 \%$ of all pharmacy graduates and African Americans constituted 58\% of all URM pharmacy graduates in $2019 .{ }^{49}$ For these reasons, this unique subset of pharmacy students may not be representative of the entire URM population within pharmacy. Furthermore, not all URM meeting participants attended the session in which the survey was conducted, limiting the generalizability of our findings. A second limitation was that the sample did not include first-year pharmacy students, limiting our understanding of the engagement, confidence, and goals of early URM pharmacy trainees. Third, survey data from non-URM students were excluded as these data have been 


\section{American Journal of Pharmaceutical Education 2021; 85 (4) Article 8365.}

reported elsewhere ${ }^{50}$ and fell outside the scope of this study. Fourth, the survey was developed by the researchers and was not previously published or validated; however, the survey development process and reliability of items promote the trustworthiness of the findings.

Despite these limitations, this study provides critical insight into an understudied issue within pharmacy education. Additional research is needed, including exploring the intersection of the job market and career interests, examining why students are interested in various career options, exploring and evaluating the experience of URM students, and examining strategies to effectively recruit and retain URM students in pharmacy schools. Further, in depth interviews or focus groups should be considered to better understand the participants' responses. This study, and those to come, will be critical to ensuring that pharmacy and pharmacy education are equipped with evidence-based strategies for promoting the recruitment, retention, and placement of URM students in the profession of pharmacy.

\section{CONCLUSION}

Despite numerous calls for research into diversity and inclusion in pharmacy and pharmacy education, the career interests and experiences of URM student pharmacists are understudied. While many of the survey participants had engaged in community pharmacy settings and indicated having confidence in pursuing a career in this area, most indicated an interest in working in hospital pharmacy. In contrast, very few participants had experience with or confidence in pursuing a career in pharmacy industry or academia. These findings align with the changing landscape of health care towards clinical pharmacy and support other research that emphasizes the evolving role of pharmacists within these health systems. This work contributes to a small yet growing body of diversity research in pharmacy education and provides a first step toward better understanding how to engage and instill career confidence in URM students.

\section{ACKNOWLEDGMENTS}

The authors acknowledge Darryl Lewis, PharmD, for assisting with data collection. We also thank the survey participants and those that provided feedback along the way.

Data from this manuscript were presented as part of a poster at the 2018 American Association of Colleges of Pharmacy annual meeting.

\section{REFERENCES}

1. The rationale for diversity in the health professions: A review of the evidence. Department of Health and Human Services, Health
Resources Administration, Bureau of Health Professions. 2006. semanticscholar.org/6df3/f71b73df07800b82250c2bf87ce594bbf667. pdf?ga $=2.211986580 .144191368 .1567996445-669364661$.

1567996445. Accessed March 3, 2021.

2. US Census Bureau Public Information Office. 2010 Census Shows America's Diversity. https:/www.census.gov/newsroom/releases/ archives/2010_census/cb11-cn125.html. Published May 19, 2016. Accessed February 18, 2020.

3. U.S. Census Bureau. Population Estimates. (V2019) [data file]. https://www.census.gov/quickfacts/fact/table/US/IPE12021.

Accessed February 18, 2020.

4. Teixeira R, Frey WH, Griffin R. States of change: the demographic evolution of the American electorate, 1974-2060. Center for American Progress. 2015; https://

cdn.americanprogress.org/wp-content/uploads/2015/02/SOCreport1.pdf. Accessed February 18, 2020.

5. Employed persons by detailed occupation, sex, race, and Hispanic or Latino ethnicity. U.S. Bureau of Labor Statistics. https://www.bls. gov/cps/aa2019/cpsaat11.htm. Published January 18, 2019. Accessed July 17, 2019.

6. Jackson CS, Gracia JN. Addressing health and health-care disparities: the role of a diverse workforce and the social determinants of health. Public Health Rep. 2014;129 Suppl 2(Suppl 2):57-61. doi:10.1177/00333549141291S211

7. Cooper-Patrick L, Gallo JJ, Gonzales JJ, et al. Race, gender, and partnership in the patient-physician relationship. JAMA. 1999;282(6): 583-589.

8. Cooper LA, Powe NR. Disparities in patient experiences, health care processes, and outcomes: the role of patient-provider racial, ethnic, and language concordance. Commonwealth Fund. New York, NY; 2004

9. Echeverri M, Brookover C, Kennedy K. Assessing pharmacy students' self-perception of cultural competence. J Health Care Poor Underserved. 2013;24(10):64-92.

10. Saha S, Taggart SH, Komaromy M, Bindman AB. Do patients choose physicians of their own race? Health Affairs. 2000;19(4): 76-83.

11. Gee GC, Ford CL. Structural racism and health inequities: old issues, new directions. Du Bois Rev. 2011;8(1):115-132. doi:10.1017/ S1742058X11000130

12. Kington R, Tisnado D, Carlisle DM. Increasing racial and ethnic diversity among physicians: an intervention to address health disparities? In: Smedley BD, Stith AY, Colburn L, Evans CH, eds. The Right Thing to Do, The Smart Thing to Do: Enhancing Diversity in the Health Professions. Washington, DC: National Academy Press, 2001.

13. Komaromy M, Grumbach K, Drake M, et al. The role of Black and Hispanic physicians in providing health care for underserved populations. N Engl J Med. 1996; 334:1305-1310.

14. White C, Conway JM, Davis PK, et al. AACP Special Taskforce white paper on diversifying our investment in human capital. Am J Pharm Educ. 2017;81(8):S13. doi:10.5688/ajpeS13

15. Strategic Plan. American Association of Colleges of Pharmacy. https://www.aacp.org/sites/default/files/2018-10/aacp-strategicplan.pdf. Accessed February 18, 2020.

16. AACP Ad Hoc Committee on Affirmative Action and Diversity. Final Report. Alexandria, Va: American Association of Colleges of Pharmacy. https://www.aacp.org/sites/default/files/

affirmativeactiondiversitycmte102000.pdf. Accessed February 20, 2020.

17. Hayes B. Increasing the representation of underrepresented minority groups in US colleges and schools of pharmacy. Am J Pharm Educ. 2008;72(1):14. doi:10.5688/aj720114 


\section{American Journal of Pharmaceutical Education 2021; 85 (4) Article 8365.}

18. Bush AA. A conceptual framework for exploring the experiences of underrepresented racial minorities in pharmacy school. Am J Pharm Educ. 2020; 84(1):7544. doi:10.5688/ajpe7544.

19. Yanchick VA, Baldwin JN, Bootman JL, Carter RA, Crabtree BL, Maine LL. Report of the 2013-2014 Argus Commission: diversity and inclusion in pharmacy education. Am J Pharm Educ. 2014;78(10):Article S21. doi:10.5688/ajpe7810S21

20. Savage LM, Beall JW, Woolley TW. Factors that influence the career goals of pharmacy students. Am J Pharm Educ. 2009;73(2):28. doi:10.5688/aj730228

21. Migliore MM, Costantino RC, Campagna NA, Jr, Albers DS. Educational and career goals of pharmacy students upon graduation. Am J Pharm Educ. 2013;77(9):187. doi:10.5688/ajpe779187

22. Bush AA, McLaughlin JE, White C. A review of contemporary diversity literature in pharmacy education. Am J Pharm Educ. 2017; 81(7):5961. doi:10.5688/ajpe8175961

23. Taber K.S. The use of Cronbach's alpha when developing and reporting research instruments in science education. Res Sci Educ. 2018;48:1273-1296. https://doi.org/10.1007/s11165-016-9602-2

24. Carvajal MJ, Hardigan P. First-job preferences and expectations of pharmacy students: intergender and interethnic comparisons. $\mathrm{J} \mathrm{Am}$ Pharm Assoc (Wash). 1999;39(1):32-40. DOI: 10.1016/s10865802(16)30413-2.

25. Varner K, Mey L, Mentzel T, Glazer G, Tobias B, Seiple T. Pulse check: underrepresented minority health-care student recruitment and retention at the University of Cincinnati. J Coll Stud Ret. 2018;20(3): 388-405.

26. Bureau of Labor Statistics. U.S. Department of Labor, Occupational Outlook Handbook. Pharmacists. https:// web.archive.org/web/20200402094827/https://www.bls.gov/ooh/ healthcare/pharmacists.htm. Accessed February 6, 2020.

27. Siracuse MV, Schondelmeyer SW, Hadsall RS, Schommer JC. Third-year pharmacy students' work experience and attitudes and perceptions of the pharmacy profession. Am J Pharm Educ. 2008; 72(3):50. doi:10.5688/aj720350

28. McElhaney A, Weber RJ. Role of pharmacy residency training in career planning: a student's perspective. Hosp Pharm. 2014;49(11): 1074-1080. doi:10.1310/hjp4911-1074

29. Miller B. Pharmacy job statistics indicate a shift from retail to hospital jobs. Healthcare Consultants Pharmacy Staffing. https:// pharmacy-staffing.com/pharmacist-jobs-statistics/. Published July 31, 2019.

30. Lebovitz L, Eddington ND. Trends in the pharmacist workforce and pharmacy education. Am J Pharm Educ. 2019;83(1):7051. doi: 10.5688/ajpe 7051

31. McCarthy BC, Jr, Weber LM. Update on factors motivating pharmacy students to pursue residency and fellowship training. Am J Health Syst Pharm. 2013;70(16):1397-403. doi: 10.2146/ ajhp120354.

32. ASHP Residency Match Statistics 2020. https://natmatch.com/ ashprmp/stats/2020applstats.pdf. Accessed June 3, 2020.

33. Poon S, Nellans K, Rothman A, et al. Underrepresented minority applicants are competitive for orthopaedic surgery residency programs, but enter residency at lower rates. J Am Acad Orthop Surg. 2019;27(21):e957-e968. doi:10.5435/JAAOS-D-17-00811

34. Adelani MA, Harrington MA, Montgomery CO. The distribution of underrepresented minorities in U.S. orthopaedic surgery residency programs. J Bone Joint Surg Am. 2019;101(18):e96. doi:10.2106/ JBJS.18.00879

35. Special report: diversity in high tech. https://www.eeoc.gov/ eeoc/statistics/reports/hightech/. Published 2015.

36. Wolf M, Terrell D. The high-tech industry, what is it and why it matters to our economic future. Beyond the Numbers. Bureau of Labor Statistics, U.S. Department of Labor. 2016;5(8). https:// www.bls.gov/opub/btn/volume-5/the-high-tech-industry-what-is-itand-why-it-matters-to-our-economic-future.htm

37. Varma R. U.S. science and engineering workforce:

underrepresentation of women and minorities. Am Behav Sci. 2018; 62(5):692-697. doi:10.1177/0002764218768847.

38. The Race Connection. Education Next. https://www.educationnext. org/the-race-connection/. Published January 11, 2017.

39. Birdsall C, Gershenson S, Zunig R. Stereotype threat, role models, and demographic mismatch in an elite professional school setting. Social Science Research Network-IZA. December 2016; No. 10459. https://ssrn.com/abstract $=2895307$

40. Paredes V. A teacher like me or a student like me? Role model versus teacher bias effect. Econ Educ Rev. 2013;39:38-49. doi: 10.1016/j.econedurev.2013.12.001.

41. Allen DD. Leading the way in pharmacy education: diversity, equity and inclusion, wellness and resilience: address of the 20182019 president to the opening general session at the 2019 Annual Meeting. Am J Pharm Educ. 2019;83(6):7781. DOI: https://doi.org/ 10.5688/ajpe7781

42. Hrabowski FA. Diversity will fuel our excellence, if we let it flourish. Am J Pharm Educ. 2019;84(5):847817. DOI: https://doi.org/ 10.5688/ajpe 847817

43. Reddick RJ, Pritchett KO. "I don't want to work in a world of whiteness:" white faculty and their mentoring relationships with black students. J Professoriate. 2016;8(1):54-84.

44. Thomas VG. Career aspirations, parental support, and work values among black female adolescents. J Multicultural Counsel Development. 1986;14(4):177-185. doi:10.1002/j.2161-

1912.1986.tb00497.x.

45. Kuhnert KW, Palmer DR. Job security, health, and the intrinsic and extrinsic characteristics of work. Group \& Organization Studies. 1991;16(2):178-192. doi:10.1177/105960119101600205.

46. Maslow AH. Toward a Psychology of Being. Van Nostrand Reinhold Co. 1968.

47. Boekeloo BO, Jones C, Bhagat K, Siddiqui J, Wang MQ. The role of intrinsic motivation in the pursuit of health science-related careers among youth from underrepresented low socioeconomic populations. J Urb Health. 2015;92(5):980-994. doi:10.1007/s11524015-9987-7.

48. Dewsbury BM, Taylor C, Reid A, Viamonte C. Career choice among first-generation, minority STEM college students. J Microbiol Biol Educ. 2019;20(3):20.3.51. doi:10.1128/jmbe.v20i3.1775

49. Fall 2019 Degrees Conferred - Profile of Pharmacy Students. American Association of Colleges of Pharmacy. https://www.aacp. org/sites/default/files/2020-05/fall-2019-pps-degrees-conferred.pdf. Published 2020. Accessed November 23, 2020.

50. Patel A, McLaughlin JE, Zhang K, Bush A, Jackson A, Lewis K. Training, confidence, and career goals in underrepresented minority students. Poster presented at: 117th Annual Meeting of the American Association of Colleges of Pharmacy; July 23-27, 2016; Anaheim, CA. 